\title{
EDITORIAL
}

\section{Compreendendo o atual momento da educação superior brasileira: cultivando a mais lúcida consciência}

\author{
Understanding the current moment of Brazilian Higher Education: \\ cultivating lucid conscience
}

\author{
Milena Pavan Serafim ${ }^{1}$ \\ ${ }^{1}$ Universidade Estadual de Campinas | Programa de Pós-Graduação Interdisciplinar em \\ Ciências Humanas e Sociais \\ Campinas | SP | Brasil. Contato: milenaps@unicamp.br \\ https://orcid.org/0000-0002-7541-4182
}

DOI: http://dx.doi.org/10.1590/S1414-4077

Este é um artigo publicado em acesso aberto sob uma licença Creative Commons

https://creativecommons.org/licenses/by-nc/4.0/

A presente Revista surgiu, em 1996, fruto de um intenso debate entre os pesquisadores da área de educação superior, que buscavam refletir as normativas propostas pelo Ministério da Educação (MEC) na época, em especial, os impactos do instrumento implementado denominado Provão, e os próprios dirigentes do MEC. A Revista, desde então, tem um papel histórico importante no cenário de reflexão e produção de conhecimentos referentes à educação superior, ancorado na percepção de que a universidade, e portanto o conhecimento gerado nela, é e deve ser visto primordialmente como bem público, sendo este sempre e a qualquer custo resguardado.

Kerr (2001), em seu texto "Os Usos da Universidade”, afirma que das 85 instituições existentes em 1520, cujas funções existentes são semelhantes ao que temos hoje, 70 eram Universidades. Boaventura de Souza Santos, analisando o diálogo entre Kerr e Jaspers, infere a esse fato a missão eterna da Universidade: "é o lugar onde por concessão do Estado e da Sociedade uma determinada época pode cultivar a mais lúcida consciência de si própria" (SANTOS, 1989, p. 12). Esse local de consciência vem sendo, nos últimos meses, confrontado sistematicamente.

Sem a prerrogativa de esgotar a reflexão, mas nos mantendo firme no propósito de refletir sobre o papel da Universidade e da Educação, tão precioso a esta revista, nos lançamos neste editorial a buscar compreender -sem esgotar o debate - o contexto de frenéticos ataques 
de dirigentes públicos às universidades e explicar o surgimento de propostas como o Programa Future-se.

$\mathrm{O}$ atual governo em tão poucos meses acumulou falas e atos proferidos contra a educação, universidades, corpo docente, universitários, etc., jamais vistos desde o regime civilmilitar. Um manifesto emblemático de ex-ministros da Educação, de diferentes governos e ideologias, demonstra a gravidade. A preocupação com a manutenção do Fundo de Manutenção e Desenvolvimento da Educação Básica e de Valorização dos Profissionais da Educação (FUNDEB) e com as ameaças às liberdades e a autonomia universitária foi o cerne desse posicionamento.

É sobre o ponto da ameaça à liberdade e autonomia universitária gostaria de me deter. Discutir liberdade e autonomia universitária requer, primeiramente, discutir que tipo de organização é a universidade. Para isso, recorremos às discussões de Musselin (2006). As perguntas que precisam ser levantadas são: A universidade é uma organização igual a outras? Que tipo de organização é a Universidade? A universidade é uma organização complexa, que possui suas particularidades, inerentes às próprias atividades desenvolvidas no seu ambiente e à multiplicidade de tarefas as quais ela potencializa. O ensino e a pesquisa (aliadas à extensão) são diferentes das encontradas em outras atividades de trabalho (MUSSELIN, 2006). Assim, como ponto de partida reconhecemos que as universidades não são organizações "comuns", elas são específicas.

Cada Universidade está inserida em um contexto com uma capacidade organizativa, com um amadurecimento que lhe é próprio, portanto, encaixá-las em categorias rígidas é difícil. Isso não quer dizer que elas não possuem características semelhantes, que são conformadas pelas normativas estatais. No Brasil, a Constituição Federal de 1988 (artigo 207) proporcionou a base das estruturas universitárias brasileiras: “Art. 207. As universidades gozam de autonomia didático-científica, administrativa e de gestão financeira e patrimonial, e obedecerão ao princípio de indissociabilidade entre ensino, pesquisa e extensão”. Neste sentido são comuns a elas os imperativos da autonomia e da indissociabilidade das funções da universidade.

Alguns autores, como Cohen, March e Olsen (1972), caracterizam a Universidade como anarquias organizadas, outros reconhecem uma certa diversidade de modelos, espelhados modelos nacionais, tais como modelo humboldtiano, Napoleônico, Norte-Americano, etc. Outros, como Mintzberg (1979), definem universidades como burocracias profissionais. Entretanto, eles compartilham de duas premissas: liberdade de cátedra e hierarquia meritocrática. 
A autonomia universitária reconhece e é sustentada pela liberdade de cátedra. Respeitadas as condutas e normas científicas, apontadas por Merton (1940), as atividades concernentes à docência, escolhas metodológicas, práticas de ensino, assim como as os temas de pesquisa, são autônomas. Para além de ser um direito constitucional, a liberdade acadêmica é base necessária dentro do processo de construção de conhecimento. A Universidade não produz parafusos (elemento padronizado). Ela gera diferentes tipos de conhecimento, podendo ser este básico ou aplicado, e esses só poderão ser plenamente constituídos e socialmente relevantes, se o processo criativo e disruptivo inerente a eles forem garantidos.

Reconhecemos que há desafios em relação à autonomia universitária. As Universidades Paulistas comemoram seus 30 anos de autonomia neste ano. O percurso até os dias de hoje demonstra que os desafios se apresentam, mas que vem sendo paulatinamente superados. Uma organização, ainda mais sendo pública, é imersa em uma rede complexa de fatores internos e externos que condicionam a sua trajetória. As teorias organizacionais podem explicar/analisar uma instituição por diferentes lupas, tais como: Ecologia das Populações (HANNAN; FREEMAN, 1977); Dependência de Recursos (PFEFFER; SALANCIK, 1978; HALL, 1990); Contingência Estrutural (WOODWARD, 1965); Novo Institucionalismo (MEYER; ROWAN, 1991), etc. Ao adentrarmos ao universo das universidades, verificam-se elementos coexistentes dessas teorias.

As universidades ainda estão ganhando maturidade institucional, natural ao seu processo constituinte e temporal. Paralelamente, visualiza-se nessa trajetória um crescimento e expansão da atuação dessas universidades, conformado claro por vários fatores. Um deles deve ser creditado à conquista da autonomia universitária, do poder de escolha pela própria comunidade científica, o que não se configura em isolamento da sociedade, mas, pelo contrário, em maior potencial de aproximação.

A despeito disso, a confusão intencional criada por aqueles que reconhecem liberdade de cátedra, generalizando fatos isolados, como balbúrdia, precisa ser contextualizada dentro de um projeto de acirramento da crise pela qual as universidades vêm passando, culminando no lançamento do Programa Future-se. Há um propósito no aparente "caos" - perseguição midiática às universidades federais, gerar ideação à sociedade sobre a "falência" institucional das universidades públicas.

Future-se - Programa Institutos e Universidades Empreendedoras e Inovadoras. Iniciase com o nome, que traz a prerrogativa de que as universidades, no modelo atual, são do pretérito. O programa busca, por meio da contratualização com uma Organização Social (OS), 
gerir as atividades-fim das Instituições Federais de Ensino Superior, em especial àquelas concernentes à pesquisa, inovação, internacionalização e gestão.

O Programa vem com uma nova roupagem. A tentativa de inserir o modelo de OSs nas universidades não é recente. Entretanto, quatro aspectos nos chamam atenção:

a) A OS faria a gestão das atividades de ensino, pesquisa e inovação;

b) Maior atratividade de processos inovativos, atividades empreendedoras;

c) Maior flexibilidade na dedicação exclusiva dos servidores, propiciando facilidade na relação entre docente e setor privado. Servidores públicos poderão prestar serviços individuais sem contrapartida à universidade.

d) Relação contratual entre Universidades e OS seria gerida por um corpo de gerentes privados e se daria por meio de um contrato de gestão.

Essas propostas, em maior ou menor medida, conflitam diretamente com a missão da universidade que é garantir a educação enquanto bem público. Permitir com que a gestão das universidades seja terceirizada é abrir um leque de possibilidades, em especial a mercadorização do ensino e a mercantilização estrita da pesquisa. Ao partir da premissa de que a educação é uma mercadoria, a contratualização se baseará em métricas de ganhos de produtividade, que rapidamente escalará para o reconhecimento de que a formação deve ser restrita a algumas carreiras "mais produtivas" e que seu conteúdo deve servir ao mercado de trabalho. Atender aos imperativos formativos do mercado, é restringir o elemento principal da geração de inovação: quebras de paradigmas. A formação de mão-de-obra estritamente barrará processos inovativos, conflitante, portanto, ao outro aspecto da proposta. Isso levaria a um espiral de baixa capacidade inovativa e atratividade do setor produtivo. Paralelamente, vale apontar que a proposta desconhece o cenário produtivo brasileiro. Vários estudos apontam que nossa baixa capacidade inovativa decorre do perfil das empresas brasileiras, avessas ao risco inerente ao processo de inovação (que é custoso e altamente arriscado), e altamente dependente do estado para efetivar atividades de pesquisa e desenvolvimento (P\&D) (DAGNINO, 2003; DIAS; SERAFIM, 2014; DE NEGRI, 2012).

Reconhecemos que a proposta ainda está bastante incipiente, mas a premissa que a sustenta é de que, a educação sendo uma mercadoria, qualquer OSs poderá geri-la melhor que a própria universidade.

As reflexões de Santos (1989) sobre as crises da Universidade, apesar de estarem pautadas em outro contexto, são absolutamente atuais para explicar o porquê dessa proposta ter eco no presente momento. Podemos compreender este contexto como um fenômeno potencializado pelo acirramento das três crises apontadas pelo autor: i) a crise de hegemonia, 
que é alavancada pela perda de poder da universidade frente à sociedade; ii) crise de legitimidade, perda da crença enquanto local que resguarda do conhecimento; e iii) crise institucional, pressupostos organizacionais são suplantados por outros modelos considerados mais eficientes. Mas também por dois processos recentes retratados por Santos (2011): desinvestimento do Estado na universidade pública e a globalização mercantil da universidade (p. 21):

\begin{abstract}
O primeiro nível consiste em induzir a universidade pública a ultrapassar a crise financeira mediante a geração de receitas próprias, nomeadamente através de parcerias com o capital, sobretudo industrial. [...] O segundo nível consiste em eliminar tendencialmente a distinção entre universidade pública e universidade privada, transformando a universidade, no seu conjunto, numa empresa, numa entidade que não produz apenas para o mercado mas que se produz a si mesma como mercado (SANTOS, 2011, p. 21).
\end{abstract}

Não é de hoje que as Universidades caminham no limiar de abandonar sua missão tradicional e avançar em outras relações (BENTO, 2014). Cabe a nós reconhecermos que, em alguma medida, falhamos por omissão ou ação e somos corresponsável pela crise que a universidade está passando e também pela crise cultural, ética, moral e social que grassa no mundo. Faz-se necessário, portanto, mais do que nunca recuperar a provocação de Bento (2014): ressurgir do sarcófago ou do leito de Procrustes e reafirmar o nosso compromisso social e civilizatório.

\title{
Referências
}

BENTO, Jorge Olímpio. Do estado da universidade: metida num sarcófago ou no Leito de Procrustes? Avaliação, Campinas; Sorocaba, v. 19, n. 3, p. 689-721, nov. 2014. Disponível em: http://periodicos.uniso.br/ojs/index.php/avaliacao/article/view/2057

COHEN, Michael D., MARCH, J. G.; OLSEN, J.P. A Garbage can model of organizational choice. Administrative Science Quarterly, Ithaca, NY, v. 17, n. 1, p. 1-25, 1972.

DAGNINO, Renato. A relação universidade-empresa no Brasil e o" argumento da hélice tripla". Revista Brasileira de Inovação, Rio de Janeiro, v. 2, n. 2, p. 267-307, 2003.

DIAS, Rafael; SERAFIM, Milena. A política científica e tecnológica brasileira nos anos 2000 e a "agenda da empresa": um novo rumo? In: MARINHO, M. G. et al. Abordagens em ciência, tecnologia e sociedade. Santo André: Universidade Federal do ABC, 2014. p. 141 164.

DE NEGRI, Fernanda. Elementos para a análise da baixa inovatividade brasileira e o papel das políticas públicas. Revista USP, São Paulo, n. 93, p. 81-100, 2012. 
HALL, R.H. Desarrollos recentes en teoria organizacional: una revision. Ciencia y Sociedad, San Domingo, República Dominicana, v. 15, n. 4, ouc./dic. 1990.

HANNAN, M.T.; FREEMAN, J. The population ecology of organizations. American Journal of Sociology, Chicago, v. 82, n. 5, p. 929-924, 1977.

KERR, C. The uses of the university. Cambridge; Massachusetts; London; England: Harvard University Press, 2001.

MEYER, J.W.; ROWAN. Institutionalized organizations: formal structure as myth and ceremony. In: POWELL, W.W.; DIMAGGIO, P.J. The new institutionalism in organizational analysis. Chicago: University of Chicago Press, 1991.

MERTON, R. Bureaucratic Structure and Personality. Social Forces, Oxford, v. 18, n. 4, p. 560-568, may 1940. Doi: https://doi.org/10.2307/2570634.

MINTZBERG, Henry. The structuring of organizations: a synthesis of the research. Illinois: University of Illinois at Urbana-Champaign's Academy for Entrepreneurial Leadership Historical Research Reference in Entrepreneurship, 1979.

MUSSELIN, C. Are universities specific organisations? In: KRÜCKEN G.; KOSMÜTZKY, A.; TORKA M. (eds.). Towards a multiversity? Universities between global trends and national traditions. Bielefeld: Transcript Verlag, 2006. p. 63-84.

PFEFFER, J.; SALANCIK, G. The external control of organizations. New York: Harper e Raw, 1982.

SANTOS, B.S. Da idea de universidade à universidade de ideas. Revista Crítica de Ciências Sociais, Coimbra, n. 27/28, p. 11-62, 1989.

SANTOS, B.S. A Universidade no Século XXI: para uma reforma democrática e emancipatória da Universidade. 3 ed. São Paulo: Cortez, 2011.

WOODWARD, J. Industrial organizations: theory and practice. New York: Oxford University Press, 1965. 